\title{
Methods of surgical treatment of bilateral vocal fold paralysis
}

\author{
Małgorzata A. Czesak ${ }^{\circledR}$, Ewa Osuch-Wójcikiewicz ${ }^{\circledR}$, Kazimierz Niemczyk $^{\circledR}$ \\ Chair and Department of Otolaryngology, Medical University of Warsaw, Warsaw, Poland
}

\begin{abstract}
Bilateral vocal fold paralysis presents as their complete or partial immobilisation. The median or paramedian position of vocal folds contributes to the narrowing of the airway at the level of the glottis and manifests as inspiratory dyspnoea. For many years iatrogenic injury of recurrent laryngeal nerves during thyroidectomy has been viewed as the most common underlying reason. It is very often a lifethreatening condition requiring not only corticosteroid administration and intubation, which only constitute a short-term symptomatic therapy, but also surgical intervention, including tracheostomy. The most common surgical methods implemented in bilateral vocal fold paralysis include posterior cordectomy, arytenoidectomy, and, more and more commonly, re-innervation. Other techniques used in restoring airway patency include laterofixation, botulinum toxin injection, and laryngeal stimulation, which is still under research. Stem cell and gene therapy are also being researched. Notably, the main purpose of surgical treatment is the provision of airway patency with the preservation of the phonatory and protective functions of the larynx. (Endokrynol Pol 2020; 71 (4): 350-358)
\end{abstract}

Key words: bilateral vocal fold paralysis; larynx; microsurgery

\section{Introduction}

Vocal fold immobilisation means a complete or substantial limitation of vocal fold mobility. It may be due to bilateral laryngeal nerve paralysis, cricoarytenoid joint stiffness, posterior glottic stenosis, and laryngeal adhesions $[1,2]$. The diagnosis of one of the above aetiologies does not rule out the remaining ones [3].

Ten per cent of vocal fold paralysis cases are due to central paralysis associated with the damage to the structures of the central nervous system [4], such as ischaemic stroke, Arnold-Chiari malformation, myasthaenia gravis, bulbar poliomyelitis, Parkinson's disease, or multifocal white matter disease [5]. Peripheral laryngeal paralysis is considerably more common, accounting for $90 \%$ of cases. It results from damage to the vagus nerve, or the superior laryngeal or recurrent laryngeal nerve (RLN) [4], due to an iatrogenic injury (26-59\%), intubation (1-31\%), injury (1-28\%), and extralaryngeal location of cancer (5-17\%) [6]. According to some authors, thyroidectomy is becoming a less common reason for vocal fold paralysis due to the improvement of surgical techniques, the use of neuromonitoring, fine-needle aspiration biopsy, and widening indications for conservative treatment in the case of benign thyroid pathologies [5]. However, the majority of research show that thyroidectomy is still the most common cause of iatrogenic damage to the RLN [5-7]. Carotid endarterectomy, and surgeries of the oesophagus, cervical spine, heart, and lungs may also contribute to the damage of the vagus nerve.

Feehery et al. reported that intubation-associated RLN paralysis occurs as a result of neuropraxia when the cuff of the intubation tube is located directly below the vocal folds compressing RLN fibres where they penetrate through the lamina of the thyroid cartilage [5].

Chen et al. also reported that radiotherapy of the area of the head and neck may cause cranial nerve paralysis because of tissue fibrosis [7].

According to English language sources, the idiopathic aetiology encompasses from 10 to $27 \%$ of all vocal fold paralysis aetiologies, while the respective values estimated in Japanese professional papers range from 25 to $41 \%$ [8].

The diagnosis of bilateral laryngeal nerve paralysis may be made on the basis of physical examination, endoscopy, and/or electromyography of the larynx. In some cases it is necessary to perform a direct laryngoscopy to confirm the mobility in the cricoarytenoid joint by palpation [9].

Patient with bilateral vocal fold paralysis has a narrow rima glottidis due to the inability to abduct the vocal folds, impaired airway function, inspiratory dyspnoea, and vocal disruption. The degree of vocal 
disruption may vary. Additionally, in the case of simultaneous superior laryngeal nerve paralysis, marked symptoms of protective dysfunction of the larynx occur, including choking when consuming food or drinks, dysphagia, and inability to cough with expectoration [10]. The varying degree of dyspnoea and associated medical problems depends on body weight, concomitant diseases, and basic physical activity [11].

Vocal folds may be located in the median or paramedian position. However, the location changes over time. It may take several years to reach the final position of the vocal folds [12] depending on the re-innervation, synkinesis, atrophy, and the fibrosis of the denervated laryngeal muscle. Woodson claimed that the paramedian position of vocal folds is due to the intensified re-innervation of the thyroarytenoid muscle and immobility caused by the lack of abduction of the posterior cricoarytenoid muscles [13].

From 4 to $14 \%$ of patients tolerate this condition and require no surgery, while in some cases delayed decompensation may occur and surgical intervention may be necessary $[6,11]$. However, the majority of patients with bilateral vocal fold paralysis require treatment that widens the rima glottidis. Since the beginning of the $20^{\text {th }}$ century numerous operative techniques through external and then endoscopic access have been described, indicating the lack of one effective and universal method. Otolaryngologists who select a treatment modality need to find a compromise between the improvement of ventilation when widening the rima glottidis, the maintenance of vocal function, and prevention of disrupting the protective function of the larynx [14]. Constant modifications are applied to operative techniques, not only in the case of arytenoidectomy or cordectomy, but also electrical laryngeal stimulation or re-innervation $[15,16]$. Moreover, botulinum toxin injections are used in cases of synkinesis in bilateral vocal fold paralysis. Furthermore, gene therapy and stem cell therapy are in the experimental phase of research [17]. Different treatment methods and their modifications are described below.

\section{Tracheostomy}

Tracheostomy is one of the most common procedures used in cases of bilateral vocal fold paralysis. It provides a direct bypass of airway obstruction. Despite being a very effective method, it is not preferred by the majority of patients [17]; this is due to the presence of an open wound [16], necessity of long-term care, and reduced quality of life [18, 19]. Naunheim et al. reported that endoscopic techniques are less expensive than tracheostomy in the treatment of bilateral vocal fold paralysis [20]. Nevertheless, in cases of sudden and severe dyspnoea tracheostomy remains the gold standard in patients with immobilised vocal folds [21].

\section{Arytenoidectomy}

Depending on its function, the rima glottidis may be divided into the phonatory segment (anterior 2/3) and respiratory segment (posterior $1 / 3$ ). The arytenoid cartilage is the key element of the posterior part of the larynx. Arytenoidectomy (arytenoid cartilage removal) is an irreversible surgical method to widen the rima glottidis in the transverse axis. The technique is widely applied independently or in combination with partial resection of the vocal folds [15]. The first arytenoidectomy was conducted in 1916 by Baker, who simultaneously performed partial cordectomy through laryngofissure approach [22]. Iwanoff removed the arytenoid cartilage by incising the mucous membrane in the medial line of the larynx [23], while Kelly made a window in the inferoposterior part of the thyroid cartilage [24]. Another approach was described by Woodman, who incised the skin parallelly to the anterior edge of the sternocleidomastoid muscle at the level of the superior border of the thyroid cartilage accessing the cricothyroid joint posteriorly. This approach facilitated the preservation of the thyroid cartilage plate as a whole, and the remaining vocal process was sutured laterally to the inferior horn of the thyroid cartilage [25]. A more effective lateralisation and smaller vertical shift was obtained by Newman et al., who modified the above technique. The vocal process was attached via small openings in the thyroid cartilage at the level of the cricoarytenoid joint [26]. Helmus described arytenoidectomy via thyreofissure approach (only the thyroid cartilage was split) under microscopic control with the use of microinstruments that allowed for the precise dissection of the arytenoid cartilage [27]. Arytenoidectomy accessed via medial thyrotomy was performed by Perlman and Kilian, who removed the cartilage via a small incision of the mucous membrane at its medial part. They used electrocoagulation, which facilitated the achievement of haemostasis and caused the development of scar tissue resulting in the lateral positioning of vocal folds [28].

In 1948 Thornell described intralaryngeal arytenoidectomy with an endoscopic approach [29]. After temporary tracheotomy and injecting the vocal fold and the aryepiglottic fold with an anaesthetic solution, an incision was performed above the arytenoid cartilage as far as the aryepiglottic fold. The cartilage was dissected and removed via the obtained access. Additional tissue lateralisation was obtained with the use of electrocoagulation and the formation of scar tissue. An acrylic stent was placed between vocal folds for 
3-4 weeks. Kleinsasser presented a modification of this technique in 1968 [30]. He made a longitudinal incision in the central part of the superior surface of the vocal fold, removed the arytenoid cartilage and two thirds of the vocal muscle in this way and obtained submucosal hemicordectomy with arytenoidectomy. The incision into the mucous membrane was sealed with intralaryngeal sutures.

The use of lasers in surgery led to the exponential development of laryngeal microsurgery [17]. Its numerous advantages include a precise line of incision, the potential of maintaining haemostasis, and the reduction of postoperative oedema [17, 31]. Laryngoscopes offer better visibility of the operative field because it is not covered with instruments during preparation. In 1983 Ossoff et al. described endoscopic total arytenoidectomy with the use of a $\mathrm{CO}_{2}$ laser [31]. In their method most of the cartilage was removed, then the incision was prolonged laterally in order to initiate fibrosis, which facilitated vocal fold lateralisation. A slight modification was presented by Sato, who preserved the flap of the mucous membrane coating the arytenoid cartilage. Subsequently, he used fibrin glue to seal the flap over the lesion [32]. Subtotal arytenoidectomy was described by Remarcle et al. in 1996. It involved the preservation only of the posterior part of the cartilage (the so-called "shell") to avert aspiration [33]. A more extensive technique was presented by Maurizi et al., who performed laser subtotal arytenoidectomy and the resection of a substantial portion of the posterior part of the vocal fold and the vestibular fold [34]. Such an extensive procedure has not been widely implemented in spite of its $100 \%$ success rate in 39 cases reported by the authors. Crumley proposed a less radical procedure of laser medial arytenoidectomy in order to maintain better vocal quality [35]. The cartilage is removed only in the central part with the preservation of its lateral and posterior part, the vocal process, and cricoarytenoid joint. Laser medial arytenoidectomy allows for widening of the posterior part of the rima glottidis by approx. 1-2 mm. If necessary, the procedure may be conducted contralaterally after three months. Googe et al. presented endoscopic arytenoidectomy with the use of plasma coblation [36]. The method was used in one patient with a tracheostomy tube. The patient was successfully decannulated eight months later. However, no research was conducted on a larger group of patients with the use of coblation in the treatment of bilateral vocal fold paralysis [17].

\section{Cordectomy}

Cordectomy (posterior and transverse) is an irreversible method of widening the rima glottidis involving the excision of part of the vocal fold, vocal ligament, or the thyroarytenoid muscle [15]. The first cordectomy was described by Hoope in 1896, who performed simultaneous tracheotomy in patients. However, the operation did not lead to the anticipated effect $[15,37]$. Several years later, in 1908, Citelli described external cordectomy performed via thyreofissure approach [38]. Hoover presented Jackson's technique called "ventriculocordectomy", in which the vocal muscle (forming the inferior part of the laryngeal ventricle - referred to as "ventriculo-" by the author) was removed through the laryngofissure approach, vocal ligament ("cordectomy"), and the vocal process [39]. Surjan modified cordectomy performed via thyreofissure approach. He created mucous membrane folds in the larynx - one at the level of the vestibular fold and another contralaterally - in the subglottis. Such an innovation aimed at reducing the risk of stenosis [40]. Šercer reported a total submucosal bilateral resection of vestibular folds and vocal folds along with the anterior part of the arytenoid cartilage [41]. The author claimed that only the posterior part of the arytenoid cartilages was preserved above the cricoid cartilage in the "neolarynx". He observed raspy voice in patients, which was produced by the aryepiglottic folds.

After endoscopic laser surgery was implemented in the treatment of bilateral vocal fold paralysis, Dennis and Kashima presented their technique in 1989 [42]. They used $\mathrm{a} \mathrm{CO}_{2}$ laser to excise a C-shaped portion of soft tissue in the posterior part of the vocal fold with the transection of the elastic cone. They obtained decannulation in $60 \%$ of patients [42-44], but bilateral or repeated cordectomy was necessary in $30 \%$ of them [16, 42]. The technique presented by Dennis and Kashima was modified by Pia and Pisani [43]. The resected vocal fold was laterally and posteriorly widened along with a part of the vestibular fold with a $\mathrm{CO}_{2}$ laser. The mucous membrane lesion was covered with fibrin preparation. Submucosal anterior cordectomy was performed by Eckel. The arytenoid cartilage was intact, and a fold of the mucous membrane was sealed with fibrin glue to the intralaryngeal lesion [45]. The obtained results were consistent with those of conventional laser arytenoidectomy [44]. Benninger et al. also presented laser posterior cordectomy with submucosal resection of the vocal process and formation of a mucous membrane flap, which was subsequently sutured laterally to the created pocket [46].

\section{Laterofixation}

Laterofixation of the vocal fold and/or the arytenoid cartilage is a reversible method in the treatment of bilateral vocal fold paralysis in adults and children 
[17]. The technique may be applied independently or in combination with other methods of laryngeal microsurgery unilaterally or bilaterally [18]. The rima glottidis is widened without the destruction of tissues responsible for phonation [17]. According to a review by Sapundzhiev et al., the fixation of the cricoarytenoid joint accessed by laryngofissure was first described by Rethi in 1922 [15]. He used an intralaryngeal stent for 2-3 months postoperatively to maintain the mobilisation of the arytenoid cartilage laterally. A similar technique was used by Montgomery, who applied a special stainless-steel pin [15].

Endoscopic lateralisation with sutures was performed by Kirchner in 1979 [47] and Ejnell in 1982 [48]. Kirchner performed endoscopic resection of the thyroarytenoid muscle with electrocoagulation. Subsequently, he temporarily fixated the vocal fold with a suture introduced into the lumen of the larynx [47]. Ejnell et al. performed vocal fold lateralisation as an independent procedure. They visualised the larynx via direct laryngoscopy and identified the cricoarytenoid joint. Then, with the use of two externally inserted needles they tied a knot and lateralised the vocal fold [48]. Remsel modified Kirchner's technique by replacing electrocoagulation with a $\mathrm{CO}_{2}$ laser [49].

Endo-extralaryngeal access in laterofixation with the use of a specially developed needle holder was introduced by Lichtenberger [50,51], in which sutures are placed from the lumen of the larynx, through the lamina of the thyroid cartilage, and out onto the skin. He also classified laterofixation into reversible endo-extralaryngeal, laryngo-microsurgical endo-extralaryngeal lateralisation and laryngo-microsurgical endo-extralaryngeal lateralisation with arytenoidectomy [51, 52]. Initially, the resection was performed with surgical instruments, which were subsequently replaced with a $\mathrm{CO}_{2}$ laser. The modification of the above techniques was proposed by Woodson and Weiss [53, 54]. Lateralisation with sutures was performed at the level of the arytenoid cartilage. They called it "arytenoid abduction", and it caused postero-caudal traction stimulating the contraction of the posterior cricoarytenoid muscle.

\section{Laryngeal stimulation}

Research on the functional electrical stimulation of paralysed laryngeal muscles has been conducted for a few decades [55]. The concept of functional electrical stimulation of paralysed muscles of the head, neck, and chest was first introduced by Zealear and Dedo [55]. In 1996 Zealear published a paper in which he confirmed that laryngeal stimulation with the use of an external device was an effective method for the treatment of vocal fold paralysis [56]. Several years later his team implanted a stimulator with electrodes in seven patients [57]. Li et al. reported that unilateral stimulation was an effective treatment, which surpassed posterior cordectomy as regards postoperative ventilation and vocal outcomes [58]. Research on unilateral electrical laryngeal stimulation was also described by Mueller et al. $[59,60]$. They implanted minimally invasive electrodes activated with an external stimulator attached to the chest wall in nine patients with bilateral vocal fold paralysis. They obtained a considerable ventilation improvement without vocal deterioration in the study group. The presented results are promising. However, further research is necessary to assess the durability of electrodes and their capacity to migrate.

\section{Botulinum toxin injections}

Botox is a neurotoxin produced by Clostridium botulinum. There are seven serologically distinct toxins (A-G), with types $A$ and $B$ being the most commonly used in medicine. The neurotoxin inhibits the release of acetylcholine from axon ending leading to flaccid paralysis [17]. In the treatment of bilateral vocal fold paralysis botulinum toxin is used to block laryngeal synkinesis. It is a movement disorder resulting from the inappropriate re-innervation following RLN damage. Synkinesis occurs when axons of RLN adductor penetrate the abductor muscle (posterior cricoarytenoid muscle) and/or axons of the abductor integrate into the adductor muscles (thyroarytenoid muscle, lateral cricoarytenoid muscle, and interarytenoid muscles) [61,62]. Synkinesis may also occur in the case of double innervation of the same motor end-plate by afferent and efferent motor neurons [63]. The diagnosis of abnormal re-innervation may be made on the basis of stroboscopic examination or electromyography of the larynx [64]. Marie et al. were the first to report a case of Botox injected bilaterally to adductor muscles as a treatment for bilateral vocal fold paralysis. Ventilation improvement was obtained [65]. Botulinum toxin may be applied unilaterally or bilaterally, via external access monitored with laryngeal electromyography and flexible nasofiberoscope or intralaryngeally via direct laryngoscopy under general anaesthesia. According to Daniel and Cordona, injection of botulinum toxin type A into the cricothyroid muscles is a quick, effective, and noninvasive modality in bilateral vocal fold paralysis and gives the possibility of avoiding tracheotomy in the patient [66]. Smith et al. injected Botox into the thyroarytenoid muscles in 10 children (additional injections were administered into the cricothyroid muscles in two patients) with bilateral vocal fold paralysis under general anaesthesia [67]. Ventilation markedly improved in four patients. According to Sahim et al., bilateral injection of botulinum 
toxin provides temporary relief in dyspnoea in patients in whom the prognosis concerning vocal fold mobility restoration remains unclear [68].

\section{Re-innervation}

The methods of surgical treatment of bilateral vocal fold paralysis described above do not restore all the functions of the larynx, such as appropriate separation of vocal folds during breathing, their closure during phonation, and the protection of the lower respiratory tract when swallowing. Therefore, laryngeal re-innervation should be the most effective modality. In 1973 Miehlike described his technique, which had been initially developed in an animal model and then performed in humans. It was called ramus posterior shunt [69]. The distal part of the posterior branch of the RLN, which innervates the abductor muscle, was transected and fixed to the main bundle of the RLN bifurcating from the vagal trunk, while the distal part of the anterior branch of the RLN, which supplies adductor muscles, was dissected [70]. The procedure did not have followers [15].

Re-innervation involves the use of the phrenic nerve, which was reported by Marina et al. [70]. A branch of the phrenic nerve is the only part that can be used for anastomosis to minimise the reduction of the mobility of the diaphragm and respiratory capacity. Li et al. obtained an improvement in 41 out of 44 patients who had undergone laryngeal re-innervation with the use of the left phrenic nerve. A marked improvement in diaphragmatic mobility (40-82\%) and respiratory function was observed in the study group over a year following the procedure [71]. A technique described by Tucker involved the implantation of a part of the omohyoid muscle or the sternohyoid muscle innervated by the hypoglossal nerve to the posterior cricothyroid muscle $[15,72]$. Long-term outcomes are very promising - improvement in the patency of the airway was noted in $80 \%$ of patients $[72,73]$. Tanaka et al. transplanted a pedunculated neuro-muscular flap using the ansa cervicalis nerve to the paraglottic space during thyroid cancer resection [74]. They did not observe vocal fold atrophy over a two-year follow up, and the phonatory function of the larynx was rated as good. However, they did not confirm the re-innervation of the thyroarytenoid muscle or the lateral cricoarytenoid muscles with EMG examination. The direct anastomosis of the ansa cervicalis nerve with the proximal part of the RLN in an animal model led to the re-innervation of adductor muscles of the larynx $[75,76]$. The results were confirmed with EMG and immunohistochemical examinations.

Marie et al. presented a slightly more complicated technique of selective re-innervation in bilateral vocal fold paralysis [77]. Posterior cricoarytenoid muscles were bilaterally re-innervated by the right superior branch of the phrenic nerve, while adductor muscles of the larynx were bilaterally re-innervated by the thyrohyoid branches of the hypoglossal nerve. Kwak et al. modified this technique by using a Y-shaped free graft to anastomose the phrenic nerve with bilateral extralaryngeal RLN stumps [78]. None of the above methods prevents synkinesis. Li et al. performed a double free graft of a nerve in selective re-innervation [79]. One Y-shaped free graft was used to anastomose the superior branch of the phrenic nerve with bilateral RLNs. The second, longer cable graft was used to attach the thyrohyoid branch of the hypoglossal nerve with the branch of RLN adductors so that axon regeneration from various donors to adductor and abductor muscles of the larynx occurred over the same length. The authors also stated that synkinesis may be prevented by the intralaryngeal transection of the interarytenoid branch of the RLN adductor and ligation of the distal nerve stump, while the proximal stump should be implanted to the posterior cricoarytenoid muscles. The technique was implemented in seven patients with the resultant improvement of aerodynamic parameters and lung function test. Moreover, EMG performed 12 months after the procedure showed full interference potentials in the thyroarytenoid muscles bilaterally during phonation and in the posterior cricoarytenoid muscles on inspiration.

Despite a variety of re-innervation techniques, a study concerning nerve reconstruction in an animal model demonstrated that free grafts of nerves or neuromuscular plates are not as histologically and physiologically effective as direct end-to-end anastomosis [80].

\section{Gene therapy}

The aim of gene therapy in the treatment of bilateral vocal fold paralysis is to deliver genes to damaged neurons and/or denervated muscles in order to facilitate the regrowth of damaged nerve cells and restoration of laryngeal muscles [17]. The genes code neurotrophic factors that promote neuron survival or growth factors that stimulate the proliferation and differentiation of stem cells [81]. Genes are delivered by vectors injected into the RLN or laryngeal muscles [17]. They are absorbed by muscle cells or nerve cell bodies via retrograde axonal transport $[82,83]$. After transduction they produce peptides that promote RLN regeneration, synapse formation, and muscle growth. Shiotani et al. published the results of their research conducted on a rat model. They injected a gene - insulin-like growth factor 1 - to the thyroarytenoid muscle of denervated larynges. They observed a substantial increase in the 
diameter of muscle fibres and the percentage of motor plates adjacent to axons in the muscle in the study group compared to the control group [84-86]. Saito et al. conducted a study in which an adenovirus vector that coded the neurotrophic factor arising from a line of glial cells was injected into the nucleus ambiguus after transecting the vagus nerve [87]. They noted a reduction in the loss of motoneurons in the nucleus ambiguus after four weeks following the injection and the resumption of neural function via the increased suppression of the activity of nitric oxide synthase and amelioration of the immunoreactivity of choline acetyltransferase. Araki et al. published the results of an injection of an adenovirus vector with a neurotrophic factor arising from a line of glial cells into the crushed RLN in a rat model [88]. They demonstrated that the study group animals developed a markedly larger axon diameter, improved remyelination, and an increased velocity of nerve conduction in comparison with the control group. However, the studies are in the experimental phase in animals. The results revealed that the method does not prevent the occurrence of synkinesis [17, 82].

\section{Stem cell therapy}

Stem cell transplantation is a method facilitating tissue regeneration. Muscle stem cells constitute a good basis for the attenuation of the atrophy of muscle bulk and contribute to its regrowth. In 2007 Halum et al. described the use of autologous stem cells arising from muscles in the treatment of bilateral vocal fold paralysis in a rat model [89]. They observed poor adduction of vocal folds after the activation of glottic closure reflex in two out of eight study group animals, while no such response was noted in the control group. Nishio et al. injected adipose-derived regenerative cells into the denervated vocal fold in pigs [90]. They reported the hypertrophy of the muscle fibre of the thyroarytenoid muscle over the month after the injection. Currently, research is being conducted on stem cell therapy. Similarly to gene therapy, this method does not prevent laryngeal synkinesis [17].

\section{Discussion}

The main purpose of the treatment of bilateral vocal fold paralysis is to facilitate effortless breathing in the patient. Nevertheless, the provision of good quality of life in those patients also includes the restoration of the remaining functions of the larynx, such as phonation and swallowing. According to Jackowska et al., the most important indices of treatment effectiveness in patients with tracheostomy are the rate and time of decannulation [91]. Therefore, it seems to be of utmost importance to avert tracheostomy by the fastest possible revision of the neck in case of iatrogenic bilateral vocal fold paralysis, and to perform end-to-end anastomosis if nerve discontinuation is confirmed. According to the literature, spontaneous restoration of vocal fold mobility is highly uncommon, so numerous surgical techniques have been developed to widen the rima glottidis in patients whose normal laryngeal function is not spontaneously restored. Progress was initially obtained with the introduction of endoscopic surgery, and then with $\mathrm{CO}_{2}$ laser usage. The advantages of the method include its precision, provision of haemostasis, and the reduction of intraoperative oedema [92]. However, the techniques are not ideal, as they may lead to the development of granulation tissue, adhesions, vocal deterioration, dysphagia, aspiration, and the inflammation of cricoid cartilage perichondrium. The procedures of static glottic enlargement consist of the removal of laryngeal tissue (arytenoidectomy, cordectomy) or shifting anatomic structures (laterofixation of the vocal fold or arytenoid abduction). They are the most common and provide the instant effect of improving airway function. Moreover, laterofixation may be regarded as an alternative to tracheostomy, because of its reversibility and minimal impairment of vocal and swallowing functions [17]. Other techniques, such as Botox injections, re-innervation, or laryngeal stimulation, are indicated in patients with bilateral vocal fold paralysis in whom laryngeal synkinesis is observed. The techniques involve the physiological restoration of laryngeal function without the necessity to perform tissue resection. Gene therapy and stem cell therapy are currently in the experimental phase in animal models. They aim at the promotion of the regrowth of neurons and atrophic muscle cells. However, they do not prevent the development of synkinesis.

Two modalities are preferred at the Department of Otorhinolaryngology, Head and Neck Surgery of the Medical University of Warsaw. The selection of a modality depends on the duration of bilateral vocal fold paralysis. Laryngeal re-innervation including end-to-end anastomosis in the case of nerve discontinuation is performed for the first six months following iatrogenic bilateral injury to the RLN. Laser posterior cordectomy combined with partial arytenoidectomy in selected cases is performed if over six months have passed since the diagnosis of bilateral vocal fold paralysis.

\section{Conclusions}

In conclusion, the treatment of bilateral vocal fold paralysis constitutes a considerable challenge for ENT physicians. The preservation of functional voice, prevention of aspiration and dysphagia, and simultaneous 
improvement of airway function is particularly difficult. Despite the fact that a variety of operative techniques are available, their effectiveness has been compared and no distinct consensus has been developed as regards the best modality.

\section{References}

1. Kashima HK. Bilateral vocal fold motion impairment: pathophysiology and management by transverse cordotomy. Ann Otol Rhinol Laryngol. 1991; 100(9 Pt 1): 717-721, doi: 10.1177/000348949110000905, indexed in Pubmed: 1952662

2. Hillel AD, Benninger M, Blitzer A, et al. Evaluation and management of bilateral vocal cord immobility. Otolaryngol Head Neck Surg. 1999; 121(6): 760-765, doi: 10.1053/hn.1999.v121.a98733, indexed in Pubmed: 10580234.

3. Hillel A, Johns M. Endoscopic carbon dioxide laser cordotomy and partial arytenoidectomy for the treatment of bilateral vocal fold paralysis. Operative Techniques in Otolaryngology — Head and Neck Surgery. 2012; 23(2): 124-127, doi: 10.1016/j.otot.2011.11.004.

4. Orzechowska M, Kaźmierczak H, Wierzchowska M. Ocena wyników leczenia zwężeń szpary głośni w materiale Kliniki Otolaryngologii i Onkologii Laryngologicznej w Bydgoszczy w latach 2000-2010. Otorynolaryngologia. 2012; 11(4): 163-167.

5. Feehery JM, Pribitkin EA, Heffelfinger RN, et al. The evolving etiology of bilateral vocal fold immobility. J Voice. 2003; 17(1): 76-81, doi: 10.1016/s0892-1997(03)00030-4, indexed in Pubmed: 12705820.

6. Benninger M, Bhattacharyya N, Fried M. Surgical management of bilateral vocal fold paralysis. Operative Techniques in Otolaryngology-Head and Neck Surgery. 1998; 9(4): 224-229, doi: 10.1016/s1043-1810(98)80008-0.

7. Chen HC, Jen YM, Wang CH, et al. Etiology of vocal cord paralysis. ORL J Otorhinolaryngol Relat Spec. 2007; 69(3): 167-171, doi: 10.1159/000099226, indexed in Pubmed: 17264533

8. Myssiorek D. Recurrent laryngeal nerve paralysis: anatomy and etiology. Otolaryngol Clin North Am. 2004; 37(1): 25-44, doi: 10.1016/S0030-6665(03)00172-5, indexed in Pubmed: 15062685.

9. Pinto JA, Godoy LB, Marquis VW, et al. Bilateral vocal fold immobility: diagnosis and treatment. Braz J Otorhinolaryngol. 2011; 77(5): 594-599, doi: 10.1590/s1808-86942011000500010, indexed in Pubmed: 22030967.

10. Maniecka-Aleksandrowicz B. Badania tonu podstawowego w diagnostyce I rehabilitacji porażeń krtani po operacjach tarczycy. Rozprawa Doktorska. Warszawska Akademia Medyczna, Warszawa 1990.

11. Kleinsasser O, Nolte E. Endolaryngeale Arytaenoidektomie und submuköse partielle Chordektomie bei bilateralen Stimmlippenlähmungen. Laryngo-Rhino-Otologie. 2008; 60(08): 397-401, doi: 10.1055/s-2007-1008753.

12. Mawaddah A, Marina MB, Halimuddin S, et al. A Ten-Year Kuala Lumpur Review on Laser Posterior Cordectomy for Bilateral Vocal Fold Immobility. Malays J Med Sci. 2016; 23(4): 65-70, doi: 10.21315/mjms2016.23.4.9, indexed in Pubmed: 27660547.

13. Woodson G. Evolving concepts of laryngeal paralysis. J Laryngol Otol. 2008; 122(5): 437-441, doi: 10.1017/S002221510700045X, indexed in Pubmed: 17892603.

14. Misiołek M, Kłębukowski L, Lisowska G, et al. Przydatność arytenoidektomii laserowej i laterofiksacji w leczeniu obustronnego porażenia fałdów głosowych. Otolaryngol Pol. 2012; 66(2): 109-116, doi: 10.1016/s0030-6657(12)70757-6.

15. Sapundzhiev N, Lichtenberger G, Eckel HE, et al. Surgery of adult bilateral vocal fold paralysis in adduction: history and trends. Eur Arch Otorhinolaryngol. 2008; 265(12): 1501-1514, doi: 10.1007/s00405-008-0665-1, indexed in Pubmed: 18418622.

16. Young VN, Rosen CA. Arytenoid and posterior vocal fold surgery for bilateral vocal fold immobility. Curr Opin Otolaryngol Head Neck Surg. 2011; 19(6): 422-427, doi: 10.1097/MOO.0b013e32834c1f1c, indexed in Pubmed: 21986801.

17. Li Y, Garrett G, Zealear D. Current Treatment Options for Bilateral Vocal Fold Paralysis: A State-of-the-Art Review. Clin Exp Otorhinolaryngol. 2017; 10(3): 203-212, doi: 10.21053/ceo.2017.00199, indexed in Pubmed: 28669149.

18. Gilony D, Gilboa D, Blumstein T, et al. Effects of tracheostomy on well-being and body-image perceptions. Otolaryngol Head Neck Surg. 2005; 133(3): 366-371, doi: 10.1016/j.otohns.2005.04.025, indexed in Pubmed: 16143183.

19. DeSanto LW, Olsen KD, Perry WC, et al. Quality of life after surgical treatment of cancer of the larynx. Ann Otol Rhinol Laryngol. 1995; 104(10 Pt 1): 763-769, doi: 10.1177/000348949510401003, indexed in Pubmed: 7574252

20. Naunheim MR, Song PC, Franco RA, et al. Surgical management of bilateral vocal fold paralysis: A cost-effectiveness comparison of two treatments. Laryngoscope. 2017; 127(3): 691-697, doi: 10.1002/lary.26253, indexed in Pubmed: 27578299.

21. Lawson G, Remacle M, Hamoir M, et al. Posterior cordectomy and subtotal arytenoidectomy for the treatment of bilateral vocal fold immobility: functional results. J Voice. 1996; 10(3): 314-319, doi: 10.1016/s0892-1997(96)80013-0, indexed in Pubmed: 8865103.

22. Downey WL, Kennon WG. Laryngofissure approach for bilateral abductor paralysis. Arch Otolaryngol. 1968; 88(5): 513-517, doi: 10.1001/archotol.1968.00770010515011, indexed in Pubmed: 5684578.

23. Iwanoff A. Die exstirpation des Aryknorpels bei Kehlkopfstenose. Z Laryngol Rhinol Otol. 1913; 5: 1067-1074.

24. Kelly J. Surgical treatment of bilateral paralysis of the abductor muscles. Arch Otolaryngol. 1941; 33: 293-304.

25. Valdez TA, Wang Z, Schumann R, et al. Anterior window laryngoplasty: a new anatomic approach for posterior glottic and subglottic stensosis. Ann Otol Rhinol Laryngol. 2001; 110(6): 519-523, doi: 10.1177/0003 48940111000605, indexed in Pubmed: 11407842.

26. Newman MH, Work WP. Arytenoidectomy revisited. Laryngoscope. 1976; 86(6): 840-849, doi: 10.1288/00005537-197606000-00010, indexed in Pubmed: 933674

27. Helmus C. Microsurgical thyrotomy and arytenoidectomy for bilateral recurrent laryngeal nerve paralysis. Laryngoscope. 1972; 82(3): 491-503, doi: 10.1288/00005537-197203000-00018, indexed in Pubmed: 5021032.

28. Pearlman SJ, Killian EW. Thyrotomy approach for arytenoidectomy in bilateral abductor paralysis of the vocal cords. Ann Otol Rhinol Laryngol. 1953; 62(1): 207-212, doi: 10.1177/000348945306200126, indexed in Pubmed: 13041074

29. Thornell WC. A new intralaryngeal approach in arytenoidectomy in bilateral abductor paralysis of the vocal cords; report of three cases. Arch Otolaryngol. 1949; 50(5): 634-9, illust, doi: 10.1001/archotol.1949.00700010648010, indexed in Pubmed: 15393408.

30. Kleinsasser O. Endolaryngeale Arytenoidektomie und submuköse Hemichordektomie zur Erweiterung der Glottis bei bilateraler Abduktorenparese. Mschr Ohr Laryngorhinol. 1968; 102: 443-446.

31. Ossoff RH, Sisson GA, Duncavage JA, et al. Endoscopic laser arytenoidectomy for the treatment of bilateral vocal cord paralysis. Laryngoscope. 1984; 94(10): 1293-1297, doi: 10.1288/00005537-198410000-00006, indexed in Pubmed: 6482626.

32. Sato K, Umeno H, Nakashima T. Laser arytenoidectomy for bilateral median vocal fold fixation. Laryngoscope. 2001; 111(1): 168-171, doi: 1 0.1097/00005537-200101000-00029, indexed in Pubmed: 11192888.

33. Remacle M, Lawson G, Mayné A, et al. Subtotal carbon dioxide laser arytenoidectomy by endoscopic approach for treatment of bilateral cord immobility in adduction. Ann Otol Rhinol Laryngol. 1996; 105(6): 438-445, doi: 10.1177/000348949610500604, indexed in Pubmed: 8638894.

34. Maurizi M, Paludetti G, Galli J, et al. CO2 laser subtotal arytenoidectomy and posterior true and false cordotomy in the treatment of post-thyroidectomy bilateral laryngeal fixation in adduction. Eur Arch Otorhinolaryngol. 1999; 256(6): 291-295, doi: 10.1007/s004050050248, indexed in Pubmed: 10456277.

35. Crumley RL. Endoscopic laser medial arytenoidectomy for airway management in bilateral laryngeal paralysis. Ann Otol Rhinol Laryngol. 1993; 102(2): 81-84, doi: 10.1177/000348949310200201, indexed in Pubmed: 8427504.

36. Googe B, Nida A, Schweinfurth J. Coblator Arytenoidectomy in the Treatment of Bilateral Vocal Cord Paralysis. Case Rep Otolaryngol. 2015; 2015: 487280, doi: 10.1155/2015/487280, indexed in Pubmed: 26457217.

37. Hope G. Laryngeal obstruction: removal of a portion of the vocal cord. Internationales Centrallblatt Laryngologie Rhinologie verwandte Wissenschaften. 1896; 12: 292

38. Citelli C. Chordectomia externa und Regeneration der Stimmlippen. Ueber eine neue Behandlungsmethode aller Kehlkopfverengungen infolge dauernder Medianstellung beider Stimmlippen. Arch Laryngol Rhinol. 1908; 20: 73-97.

39. Hoover W. Bilateral abductor paralysis: operative treatment by submucous resection of the vocal cords. Arch Otolaryngol. 1932; 15: 339-355.

40. Surjan L. Die submuköse Chordektomie als glottiserweiternde Operation. HNO. 1965; 13: 231-233.

41. Sercer A. Zur operativen Therapie chronischer Kehlkopfstenosen. Mschr Ohr Laryngorhinol. 1936; 70: 1153-1158.

42. Dennis DP, Kashima H. Carbon dioxide laser posterior cordectomy for treatment of bilateral vocal cord paralysis. Ann Otol Rhinol Laryngol. 1989; 98(12 Pt 1): 930-934, doi: 10.1177/000348948909801203, indexed in Pubmed: 2589760.

43. Pia F, Pisani P, Aluffi P. CO(2) laser posterior ventriculocordectomy for the treatment of bilateral vocal cord paralysis. Eur Arch Otorhinolaryngol. 1999; 256(8): 403-406, doi: 10.1007/s004050050175, indexed in Pubmed: 10525945.

44. Eckel HE, Thumfart M, Wassermann K, et al. Cordectomy versus arytenoidectomy in the management of bilateral vocal cord paralysis. Ann Otol Rhinol Laryngol. 1994; 103(11): 852-857, doi: 10.1177/00034894941 0301105, indexed in Pubmed: 7978998. 
45. Eckel HE. Die laserchirurgische mikrolaryngoskopische Glottiserweiterung zur Behandlung der beidseitigen Rekurrensparese. Laryngo-Rhino-Otologie. 2008; 70(01): 17-20, doi: 10.1055/s-2007-997976.

46. Benninger M, Bhattacharyya N, Fried M. Surgical management of bilateral vocal fold paralysis. Operative Techniques in Otolaryngology-Head and Neck Surgery. 1998; 9(4): 224-229, doi: 10.1016/s1043-1810(98)80008-0.

47. Kirchner FR. Endoscopic lateralization of the vocal cord in abducto paralysis of the larynx. Laryngoscope. 1979; 89(11): 1779-1783, doi: 10. 1288/00005537-197911000-00010, indexed in Pubmed: 502699.

48. Ejnell $\mathrm{H}$, Bake B, Hallen $\mathrm{O}$, et al. new simple method of laterofixation and its efects on orolaryngeal airway resistance and fonation. Acta Otolaryngol. 1982; 386: 196-197.

49. Remsen K, Lawson W, Patel N, et al. Laser lateralization for bilateral vocal cord abductor paralysis. Otolaryngol Head Neck Surg. 1985; 93(5): 645-649, doi: 10.1177/019459988509300514, indexed in Pubmed: 3932934

50. Lichtenberger G. Endo-extralaryngeal needle carrier instrument. Laryngoscope. 1983; 93(10): 1348-1350, doi: 10.1002/lary.1983.93.10.1348, indexed in Pubmed: 6353100.

51. Lichtenberger G. Reversible immediate and definitive lateralization of paralyzed vocal cords. Eur Arch Otorhinolaryngol. 1999; 256(8): 407-411, doi: 10.1007/s004050050176, indexed in Pubmed: 10525946.

52. Lichtenberger G. Comparison of endoscopic glottis-dilating operations. Eur Arch Otorhinolaryngol. 2003; 260(2): 57-61, doi: 10.1007/s00405-002-0505-7, indexed in Pubmed: 12582779.

53. Woodson G, Weiss T. Arytenoid abduction for dynamic rehabilitation of bilateral laryngeal paralysis. Ann Otol Rhinol Laryngol. 2007; 116(7): 483-490, doi: 10.1177/000348940711600702, indexed in Pubmed: 17727078.

54. Woodson G. Arytenoid abduction for bilateral vocal fold immobility. Curr Opin Otolaryngol Head Neck Surg. 2011; 19(6): 428-433 doi: 10.1097/MOO.0b013e32834cd564, indexed in Pubmed: 22001662.

55. Zealear DL, Dedo HH. Control of paralyzed axial muscles by electrica stimulation. Trans Sect Otolaryngol Am Acad Ophthalmol Otolaryngol. 1977; 84(2): 310, indexed in Pubmed: 898504

56. Zealear DL, Rainey CL, Herzon GD, et al. Electrical pacing of the paralyzed human larynx. Ann Otol Rhinol Laryngol. 1996; 105(9): 689-693, doi: 10.1177/000348949610500904, indexed in Pubmed: 8800054.

57. Zealear DL, Billante CR, Courey MS, et al. Reanimation of the paralyzed human larynx with an implantable electrical stimulation device. Laryngoscope. 2003; 113(7): 1149-1156, doi: 10.1097/00005537-200307000-0001 0, indexed in Pubmed: 12838013.

58. Li Y, Pearce EC, Mainthia R, et al. Comparison of ventilation and voice outcomes between unilateral laryngeal pacing and unilateral cordotomy for the treatment of bilateral vocal fold paralysis. ORL J Otorhinolaryngol Relat Spec. 2013; 75(2): 68-73, doi: 10.1159/000345501, indexed in Pubmed: 23736349

59. Mueller AH, Hagen R, Pototschnig C, et al. Laryngeal pacing for bilateral vocal fold paralysis: Voice and respiratory aspects. Laryngoscope. 2017 127(8): 1838-1844, doi: 10.1002/lary.26428, indexed in Pubmed: 27943294.

60. Mueller AH, Hagen R, Foerster G, et al. Laryngeal pacing via an implantable stimulator for the rehabilitation of subjects suffering from bilateral vocal fold paralysis: A prospective first-in-human study. Laryngoscope. 2016; 126(8): 1810-1816, doi: 10.1002/lary.25792, indexed in Pubmed: 27426938.

61. Crumley RL. Laryngeal synkinesis: its significance to the laryngologist Ann Otol Rhinol Laryngol. 1989; 98(2): 87-92, doi: 10.1177/00034894890 9800201, indexed in Pubmed: 2916830.

62. Gacek RR. Morphologic correlates for laryngeal reinnervation. Laryngoscope. 2001; 111(11 Pt 1): 1871-1877, doi: 10.1097/00005537-20011100 0-00001, indexed in Pubmed: 11801962

63. Rosen M, Malmgren LT, Gacek RR. Three-dimensional computer reconstruction of the distribution of neuromuscular junctions in the thyroarytenoid muscle. Ann Otol Rhinol Laryngol. 1983; 92 (5 Pt 1): 424-429, doi: 10.1177/000348948309200503, indexed in Pubmed: 6625438.

64. Smith LJ, Rosen CA, Munin MC. Vocal fold motion outcome based on excellent prognosis with laryngeal electromyography. Laryngoscope. 2016 126(10): 2310-2314, doi: 10.1002/lary.25910, indexed in Pubmed: 27242070.

65. Marie JP, Navarre I, Lerosey Y, et al. [Bilateral laryngeal movement disorder and synkinesia: value of botulism toxin. Apropos of a case] Rev Laryngol Otol Rhinol (Bord). 1998; 119(4): 261-264, indexed in Pubmed: 9865104

66. Daniel SJ, Cardona I. Cricothyroid onabotulinum toxin A injection to avert tracheostomy in bilateral vocal fold paralysis. JAMA Otolaryngol Head Neck Surg. 2014; 140(9): 867-869, doi: 10.1001/jamaoto.2014.1515, indexed in Pubmed: 25123108.

67. Smith ME, Park AH, Muntz HR, et al. Airway augmentation and maintenance through laryngeal chemodenervation in children with impaired vocal fold mobility. Arch Otolaryngol Head Neck Surg. 2007; 133(6): 610-612, doi: 10.1001/archotol.133.6.610, indexed in Pubmed: 17576914

68. Sahin M, Aydogdu I, Akyildiz S, et al. Electromyography-Guided Botulinum Toxin Injection Into the Cricothyroid Muscles in Bilatera Vocal Fold Abductor Paralysis. Clin Exp Otorhinolaryngol. 2017; 10(2): 193-202, doi: 10.21053/ceo.2016.00241, indexed in Pubmed: 27416735.
69. Miehlike A. Rehabilitation of vocal cord paralysis. Studies using the vagus recurrent bypass anastomosis, type ramus posterior shunt. Arch Otolaryngol. 1974; 100(6): 431-441, indexed in Pubmed: 4447483.

70. Marina MB, Marie JP, Birchall MA. Laryngeal reinnervation for bilateral vocal fold paralysis. Curr Opin Otolaryngol Head Neck Surg. 2011; 19(6): 434-438, doi: 10.1097/MOO.0b013e32834c7d30, indexed in Pubmed: 22001659.

71. Li M, Chen S, Zheng H, et al. Reinnervation of bilateral posterior cricoarytenoid muscles using the left phrenic nerve in patients with bilateral vocal fold paralysis. PLoS One. 2013; 8(10): e77233, doi: 10.1371/journal. pone.0077233, indexed in Pubmed: 24098581.

72. Tucker HM. Human laryngeal reinnervation: long-term experience with the nerve-muscle pedicle technique. Laryngoscope. 1978; 88(4): 598-604 doi: 10.1002/lary.1978.88.4.598, indexed in Pubmed: 642658.

73. Tucker HM. Human laryngeal reinnervation. Laryngoscope. 1976 86(6): 769-779, doi: 10.1288/00005537-197606000-00004, indexed in Pubmed: 933669

74. Tanaka S, Asato R, Hiratsuka Y. Nerve-muscle transplantation to the paraglottic space after resection of recurrent laryngeal nerve. Laryngoscope. 2004; 114(6): 1118-1122, doi: 10.1097/00005537-200406000-000 30, indexed in Pubmed: 15179224.

75. Green DC, Berke GS, Graves MC. A functional evaluation of ansa cervicalis nerve transfer for unilateral vocal cord paralysis: future directions for laryngeal reinnervation. Otolaryngol Head Neck Surg. 1991; 104(4): 453-466, doi: 10.1177/019459989110400406, indexed in Pubmed: 1903856.

76. Zheng H, Li Z, Zhou S, et al. Experimental study on reinnervation of vocal cord adductors with the ansa cervicalis. Laryngoscope. 1996 106(12 Pt 1): 1516-1521, doi: 10.1097/00005537-199612000-00014, indexed in Pubmed: 8948614.

77. Marie JP, Dehesdin D, Ducastelle T, et al Selective reinnervation of the abductor and adductor muscles of the canine larynx after recurrent nerve paralysis. Ann Otol Rhinol Laryngol. 1989; 98(7 Pt 1): 530-536, doi: 10.1 177/000348948909800707, indexed in Pubmed: 2751212

78. Kwak PE, Friedman AD, Lamarre ED, et al. Selective reinnervation of the posterior cricoarytenoid and interarytenoid muscles: an anatomical study. Laryngoscope. 2010; 120(3): 463-467, doi: 10.1002/lary.20752, indexed in Pubmed: 20066727.

79. Li M, Zheng $\mathrm{H}$, Chen $\mathrm{S}$, et al. Selective reinnervation using phrenic nerve and hypoglossal nerve for bilateral vocal fold paralysis. Laryngoscope. 2019; 129(11): 2669-2673, doi: 10.1002/lary.27768, indexed in Pubmed: 30756404

80. Zheng H, Zhou S, Chen S, et al. An experimental comparison of different kinds of laryngeal muscle reinnervation. Otolaryngol Head Neck Surg. 1998; 119(5): 540-547, doi: 10.1016/S0194-5998(98)70122-6, indexed in Pubmed: 9807090.

81. Bijangi-Vishehsaraei K, Blum K, Zhang H, et al. Microarray Analysis Gene Expression Profiles in Laryngeal Muscle After Recurrent Laryngeal Nerve Injury. Ann Otol Rhinol Laryngol. 2016; 125(3): 247-256, doi: 10.1177/0003489415608866, indexed in Pubmed: 26530091.

82. Heavner SB, Rubin AD, Fung K, et al. Dysfunction of the recurren laryngeal nerve and the potential of gene therapy. Ann Otol Rhinol Laryngol. 2007; 116(6): 441-448, doi: 10.1177/000348940711600609, indexed in Pubmed: 17672247.

83. Rubin A, Mobley B, Hogikyan N, et al Delivery of an adenoviral vector to the crushed recurrent laryngeal nerve. Laryngoscope. 2003 113(6): 985-989, doi: 10.1097/00005537-200306000-00013, indexed in Pubmed: 12782809.

84. Flint PW, Shiotani A, O'Malley BW. IGF-1 gene transfer into denervated rat laryngeal muscle. Arch Otolaryngol Head Neck Surg. 1999; 125(3): 274-279, doi: 10.1001/archotol.125.3.274, indexed in Pubmed: 10190798.

85. Shiotani A, Saito K, Araki K, et al. Gene therapy for laryngeal paralysis. Ann Otol Rhinol Laryngol. 2007; 116(2): 115-122, doi: 10.1177/0003 48940711600207, indexed in Pubmed: 17388235.

86. Shiotani A, O'Malley BW, Coleman ME, et al. Reinnervation of motor endplates and increased muscle fiber size after human insulin-like growth factor I gene transfer into the paralyzed larynx. Hum Gene Ther. 1998; 9(14): 2039-2047, doi: 10.1089/hum.1998.9.14-2039, indexed in Pubmed: 9759931.

87. Saito K, Shiotani A, Watabe K, et al. Adenoviral GDNF gene transfer prevents motoneuron loss in the nucleus ambiguus. Brain Res. 2003; 962(1-2): 61-67, doi: 10.1016/s0006-8993(02)03933-1, indexed in Pubmed: 12543456

88. Araki K, Shiotani A, Watabe K, et al. Adenoviral GDNF gene transfe enhances neurofunctional recovery after recurrent laryngeal nerve injury. Gene Ther. 2006; 13(4): 296-303, doi: 10.1038/sj.gt.3302665, indexed in Pubmed: 16251996.

89. Halum SL, Naidu M, Delo DM, et al Injection of autologous muscle stem cells (myoblasts) for the treatment of vocal fold paralysis: a pilot study. Laryngoscope. 2007; 117(5): 917-922, doi: 10.1097/MLG.0b013e31803e8c8d, indexed in Pubmed: 17473696. 
90. Nishio N, Fujimoto Y, Suga K, et al. Autologous fat injection therapy including a high concentration of adipose-derived regenerative cells in a vocal fold paralysis model: animal pilot study. J Laryngol Otol. 2016; 130(10): 914-922, doi: 10.1017/S0022215116008707, indexed in Pubmed: 27604559.

91. Jackowska J, Sjogren EV, Bartochowska A, et al. Outcomes of CO laser-assisted posterior cordectomy in bilateral vocal cord paralysis in 132 cas- es. Lasers Med Sci. 2018; 33(5): 1115-1121, doi: 10.1007/s10103-018-2478-9, indexed in Pubmed: 29557514.

92. Dispenza F, Dispenza C, Marchese D, et al. Treatment of bilateral vocal cord paralysis following permanent recurrent laryngeal nerve injury. Am J Otolaryngol. 2012; 33(3): 285-288, doi: 10.1016/j.amjoto.2011.07.009, indexed in Pubmed: 21924522. 